\title{
On the connexion between the gas-density and stratum-interval in geissler tubes
}

\section{Dr. E. Goldstein}

To cite this article: Dr. E. Goldstein (1882) On the connexion between the gas-density and stratum-interval in geissler tubes, Philosophical Magazine Series 5, 14:89, 402-403, DOI: 10.1080/14786448208627284

To link to this article: http://dx.doi.org/10.1080/14786448208627284

册 Published online: 28 Apr 2009.

Submit your article to this journal $\lceil\pi$

Џ Article views: 2

Q View related articles $₫$ 
tolerably distant catastrophe, they will console themselves by the thought that the things of this world, even the most beautiful, do not appear to be made to last for ever.

As to the fundamental experiments of Dr. Siemens, they will lose none of their importance in their eyes. The business is to surprise a secret of living nature, one of the laws of the organic world ; and their desire will be that $\mathrm{Dr}$. Siemens may pursue the course in which he has commenced so brilliantly, even though they cannot hope to have a very bright light thrown by it upon their own researches.-Comptes Rendus, October 9,1882, p. 612.

ON THE CONNEXION BETWEEN THE GAS-DENSITY AND STRATUMINTERVAI IN GEISSLER TUBES. BY DR. E. GOLDSTEIN.

Let the total length of a series of immediately consecutive strata of the positive light, of which the first is that which is next to the positive end of the tube, divided by the number of strata, be called the mean interval. The following data respecting this quantity are abstracted from experiments with dry air, hydrogen, and mixtures of the two, under such conditions of the discharge that the strata do not exhibit the to-and-fro vibrating saucer-shapes which escape any precise measurements, but appear in the so-called nebulous forms, which can be brought to a considerably greater degree of stability. In opposition to the generally current view that these clouds represent degenerations and derangements of the proper stratification, I have already* called attention to the far greater probability that they only represent the full development of that phenomenon. The thick cloudy strata stand in precisely the same relation to the thin saucer-like strata as a long-rayed tuft light at the cathode to thin films at first investing the cathode, from which, with diminishing density of the gas, the elongated rays are developed. In order to form a clear conception, I wished, further, to be able to presuppose as known that in cylindrical tubes the stratum-interval increases with increasing width of the tubet, so that, in tubes filled with air, the intervals between the individual strata, when the latter are most distinctly formed, are about equal to the diameter of the tube + .

If, now, we determine, for cylindrical tubes of different widths inserted in the current-circuit, from an equal number of strata the mean stratum-interval $\mathbf{J}, \mathrm{J}^{\prime}, \mathrm{J}^{\prime \prime}, \ldots$ for any two pressures of gas $d$ and $\delta$, we obtain constantly

$$
\frac{\mathrm{J}_{d}}{\mathrm{~J}_{\delta}}=\frac{\mathrm{J}_{d}^{\prime}}{\mathrm{J}_{\delta}^{\prime}}=\frac{\mathrm{J}^{\prime \prime}{ }_{d}}{\mathrm{~J}_{\delta}^{\prime \prime}} \ldots
$$

in words:-For cylindrical tubes of different widths, the mean stratum-interval coustantly varies in the same ratio between the same gas-pressures. Therefore, if, for example, in one of the tubes

* Wied. Ann. xii. p. 272.

$\dagger$ Monatsb. der Akad. Berlin, 1876, p. 294 ; Phil. Mag. [5] iv. p. 353.

† Wied. Ann, xii. p. 272 . 
the stratum-interval has by the rarefaction of the gas been raised to twice or three times its first-measured value, then in all the other tubes the intervals have been doubled or trebled.

The tube-diameters in my experiments varied between 2 millim. and 4 centim. The above-mentioned regularity came out, independently of whether the different cylinders formed separate vessels with two metallic electrodes each, or whether, united into a single tube, they were inserted in a line one behind another in the current.

The law is moreover found to hold good equally whether the mean interval be taken from a large or a small number of strata, provided the numbers in the different tubes be equal, although at the same time the absolute value changes. From this it can be concluded that each single interval also increases in accordance with the above-mentioned law.

The value of the mean interval is found with great regularity to be, in every tube, as much smaller as the number of strata from which it is derived is greater. Yet the amplitude of the undulation, multiplied by the greatest number of strata employed, never reaches the value of the smallest of the single intervals. Consequently, from the above law it follows that, if in any tube the magnitude of the mean stratum-interval for a series of gas-densities $D_{1}, D_{2} \ldots D_{n}$ is known, and also, for a number of other tubes, each value of the mean interval that corresponds to any one of those densities, the number of the strata which these tubes can show at all the densities from $\mathrm{D}_{1}$ to $\mathrm{D}_{n}$ can be calculated.

The proportion $\frac{\mathrm{J} d}{\mathrm{~J} \delta}=\frac{\mathrm{J}_{d}^{\prime}}{\mathrm{J}_{\delta}^{\prime}}$ permits us to conclude that the function according to which the mean interval varies with the gasdensity is the same for tubes of different widths. Experiments for the purpose of ascertaining that function gave the following result :-

If the rarefactions of the gas increase in a geometrical series, the stratum-intervals are augmented also, very nearly, in a geometrical series. But the exponents of the two series are not identical; that is, the stratum-intervals are not (as was once maintained by the other side) inversely proportional to the pressure of the gas. On the contrary the measurements prove that the intervals increase much more slowly than the rarefactions - approximately at the rate of $\frac{4}{3}$ when the rarefaction is 3 . I will defer more definite statements until I have determined the exponents with the greatest possible exactness, for which I am at present experimenting on a Toepler pump in the form described by von Hagen*.-Monctsberichte der Kön. Aliad. der Wissenschafteu zu Berline, 1881, pp. 876878 (separate impression, communicatd by the Anthor).

ON THE ELASTICITY OF RAREFIED Gases. BY E. H. AMAGAT.

This subject has already been treated by Mendeleef, Kirpitchoff and Hemilian, by Silgerström, and by myself. Those researches

* Wied. Ann. xii. p. 425. 